University of Windsor

Scholarship at UWindsor

\title{
Applying Recent Argumentation Methods to Some Ancient Examples of Plausible Reasoning
}

\author{
Douglas Walton \\ University of Windsor, Centre for Research in Reasoning, Argumentation and Rhetoric \\ Christopher W. Tindale \\ Thomas F. Gordon
}

Follow this and additional works at: https://scholar.uwindsor.ca/crrarpub

Part of the Arts and Humanities Commons

\section{Recommended Citation}

Walton, Douglas; Tindale, Christopher W.; and Gordon, Thomas F.. (2014). Applying Recent Argumentation Methods to Some Ancient Examples of Plausible Reasoning. Argumentation, 28 (1), 85-119.

https://scholar.uwindsor.ca/crrarpub/18

This Article is brought to you for free and open access by the Centre for Research in Reasoning, Argumentation and Rhetoric (CRRAR) at Scholarship at UWindsor. It has been accepted for inclusion in CRRAR Publications by an authorized administrator of Scholarship at UWindsor. For more information, please contact scholarship@uwindsor.ca. 


\title{
Applying Recent Argumentation Methods to Some Ancient Examples of Plausible Reasoning
}

\author{
Douglas Walton • Christopher W. Tindale • \\ Thomas F. Gordon
}

Published online: 10 November 2013

(C) Springer Science+Business Media Dordrecht 2013

\begin{abstract}
Plausible (eikotic) reasoning known from ancient Greek (late Academic) skeptical philosophy is shown to be a clear notion that can be analyzed by argumentation methods, and that is important for argumentation studies. It is shown how there is a continuous thread running from the Sophists to the skeptical philosopher Carneades, through remarks of Locke and Bentham on the subject, to recent research in artificial intelligence. Eleven characteristics of plausible reasoning are specified by analyzing key examples of it recognized as important in ancient Greek skeptical philosophy using an artificial intelligence model called the Carneades Argumentation System (CAS). By applying CAS to ancient examples it is shown how plausible reasoning is especially useful for gaining a better understanding of evidential reasoning in law, and argued that it can also be applied to everyday argumentation. Our analysis of the snake and rope example of Carneades is also used to point out some ways CAS needs to be extended if it is to more fully model the views of this ancient philosopher on argumentation.
\end{abstract}

Keywords Defeasible reasoning - The Carneades argumentation system · The philosopher Carneades · Evidential reasoning · Eikos ·

\footnotetext{
D. Walton $(\bowtie)$

Centre for Research in Reasoning, Argumentation and Rhetoric (CRRAR), University of Windsor, 401 Sunset Ave., Windsor, ON N9B 3P4, Canada

e-mail: dwalton@uwindsor.ca

URL: http://www.dougwalton.ca

C. W. Tindale

Centre for Research in Reasoning, Argumentation and Rhetoric (CRRAR), University of Windsor, 401 Sunset Ave., Windsor, ON N9B 3P4, Canada

T. F. Gordon

Fraunhofer FOKUS, Kaiserin-Augusta-Allee 31, 10589 Berlin, Germany

e-mail: thomas.gordon@fokus.fraunhofer.de
} 
Testing a hypothesis $\cdot$ Argument from perception $\cdot$ Argumentation schemes

\section{Introduction}

In this paper, it is shown that there is a significant connection between the ancient recognition of plausible reasoning by the Greek skeptics and Sophists and the resurgence of the notion in recent work in argumentation theory and artificial intelligence. The aims of the paper are to analyze plausible reasoning and show that it has distinctive characteristics as a type of reasoning by examining some historically important paradigm examples and by applying modern tools of argument identification and analysis to them, including argument mapping tools and defeasible argumentation schemes (Prakken et al. 2003). A special case in point is the Carneades Argumentation System (CAS), a formal mathematical model of argumentation and software visualization tool used in artificial intelligence (Gordon and Walton 2006; Gordon et al. 2007).

Plausible reasoning was acknowledged as important in ancient philosophy by the Sophists, who gave many good examples of its use (Tindale 2010). In later Greek philosophy, Carneades, the head of the Third Academy, developed a theory of plausible reasoning to reply to the objection by the opponents of the Academics that Academic skepticism left no room for rational assent in the conduct of everyday deliberations. Although the skeptics deeply explored the limits of reason and its inability to establish fundamental truth, they have often been fallaciously criticized, ignored, and not taken seriously throughout the history of philosophy (Groarke 1990, 4-5). This paper analyzes some ancient examples of plausible reasoning, most notably a very famous one attributed to Carneades, using modern argumentation methods.

Section 2 situates plausible reasoning in a modern framework by showing how the classic example of defeasible reasoning based on perception represents a distinct kind of plausible reasoning that can be used to support a conclusion subject to critical questioning. Section 3 outlines two of the most famous examples of plausible reasoning that were familiar in ancient philosophy. Both examples are analyzed to show how they represent a distinctive kind of pro-contra argumentation based on certain common forms of argument, including argument from negative consequences and argument from evidence to a hypothesis. One of these examples shows how plausible reasoning is especially important for evidential legal argumentation of the kind that takes place in a trial setting. Section 4 outlines the theory of plausible reasoning attributed to the ancient skeptical philosopher Carneades, using his famous example of the rope and snake. Section 5 shows how, although knowledge of plausible reasoning faded well into the background during the Enlightenment period, it maintained some presence in the writings of Locke and Bentham. It is shown how both Locke and Bentham continued to advocate a place for plausible reasoning, and anticipated some key features of the modern view of it found in artificial intelligence. Section 6 briefly explains CAS. Section 7 shows how this system applies to one of the examples in Sect. 3. Section 8 modifies the critical 
questions matching the argumentation scheme for argument from perception in order to pave the way for Sect. 9, which applies CAS to the rope and snake example. Section 10 presents the conclusions of the paper, and Sect. 11 considers directions for further research.

\section{What is Plausible Reasoning?}

In Pollock's leading example of defeasible reasoning $(1995,41)$, a person sees an object that looks red to him. However, he knows that the object is illuminated by a red light, and that red lights can make an object look red even when it is not. Knowing the latter defeats his reason for thinking that the light is red, but it is not a reason for drawing the conclusion that the light is not red. For as Pollock put it (41), "After all, red objects look red in red light too". The argumentation in the example can be broken down into two component arguments. The first one is this.

First Fact

This object looks red to me.

First Generalization When an object looks red, then (normally, but subject to exceptions) it is red.

First Conclusion This object is red.

Following on this first argument is a second one.

Second Fact

Second Generalization

Second Conclusion
This object is illuminated by a red light.

When an object is illuminated by a red light this can make it look red even though it is not.

The first argument does not apply.

The object may still be red, for all we know, despite the second argument above, but once the second argument has been put forward, the reason supporting the first conclusion is undercut, in Pollock's terminology. There can also be another way of analyzing what has taken place in the sequence of argumentation. The first argument was based on a defeasible generalization that admits of exceptions. The second fact provides an exception, and although the first generalization still holds in general, it has been shown that it fails in this particular case, in light of the new evidence about the case. Hence the second conclusion tells us that that the first argument is not applicable.

Pollock's perception rule 'Having a percept with content $\varphi$ is a prima facie reason to believe $\varphi$ ' will be the basis of the example from Carneades treated below. This rule is defeasible, but does not have to do with numerical probabilities. Plausibility does not essentially have to do with the statistical likelihood of what happened in a given case. In this respect, it is different from inductive reasoning of the kind identified with probability. It has to do with the way things are normally expected to go in a type of situation that is familiar both to the participants and the onlookers, or judges of the situation. Inductive reasoning is also defeasible, so it isn't defeasibility that is the defining mark of plausible reasoning. Nevertheless, defeasibility is an important characteristic of it. Sometimes this third kind of reasoning has been called plausible reasoning, as opposed to probable reasoning of 
the inductive kind. The terminology has not yet been sorted out, partly because the concept of probable reasoning as used in statistics is not unproblematic to define. Some define it using the Bayesian axioms for the probability calculus, while others define it as a relative frequency. Some distinguish between quantitative senses of probability and subjective probability, of the kind that takes a statement to be acceptable if it is reasonable to expect that it is true in light of reasonable expectations of what are normal and familiar situations. This kind of probability could equally well be classified as a species of plausible reasoning. While it is unsatisfying that the terminology in this area is so unsettled, the subject is an important one for investigation in both argumentation and artificial intelligence.

It is always a controversial question whether plausibility can be reduced to statistical probability, or to a Bayesian notion of probable reasoning of the kind expressed in the axioms for the probability calculus. Plausible reasoning has been analyzed by Rescher (1976) in a way that brings out important differences between it and probable reasoning of the inductive sort. Josephson and Josephson (1994) have strongly supported Rescher's view that plausible reasoning represents a third type of reasoning that cannot be adequately analyzed using deductive or standard inductive models. Views on what probability is vary widely. However, on one view, probabilistic reasoning bases its evaluation of reasoning on a set of exclusive and exhaustive alternatives and puts a numerical distribution of so-called probability values across the set. Plausible reasoning does not work this way, according to Rescher (1976, 30-31). Instead, it arrives at an evaluation of an inference based on the external support for each proposition that is a premise or conclusion of the inference.

Josephson and Josephson (1994, 265-272) also characterize plausible reasoning in a way that makes it different from probable reasoning. On their analysis, plausible reasoning needs to be measured by coarse-scale "confidence values" as a rough basis for guiding intelligent action, but are different from probability values. On their view, it is not helpful to treat these values using Bayesian probability calculations (270). Another type of reasoning that will turn out to be important in this paper is abductive inference, or inference to the best explanation according to the terminology of Josephson and Josephson $(1994,14)$. On their account, abductive inference takes the following form, where $H$ is a hypothesis.

- $D$ is a collection of data.

- $H$ explains $D$.

- No other hypothesis can explain $D$ as well as $H$ does.

- Therefore $H$ is probably true.

In inference to the best explanation, multiple explanations of a given fact or observation can be generated, and the best explanation is selected according to criteria that express the degree to which they conform to the evidence and their plausibility. This best explanation is then drawn as the conclusion of the inference.

What way of evaluating arguments should be used then? In CAS, evaluation of an argument as strong or weak will depend on the acceptance of the premises by an audience and on standards of proof such as preponderance of the evidence and clear and convincing evidence. Arguments will also be tested by the asking of critical questions matching an argumentation scheme. 
In this paper, we take an approach of using forms of argument that represent different kinds of plausible reasoning called defeasible argumentation schemes. Argumentation schemes include forms of arguments we are familiar with in deductive logic, like modus ponens or syllogistic argument forms. But the ones of key importance in this paper represent defeasible, plausible arguments that depend on common understanding of the way things can normally be expected to go in a kind of case familiar to speaker and hearer. Each defeasible argumentation scheme has a matching set of critical questions, and the scheme, used in conjunction with the questions, is the device for identifying, analyzing and evaluating the argument. The study of such defeasible plausible argumentation schemes has become very important in computer science, and has come to be seen as very important in modeling legal argumentation. It is recognized that they are fundamentally important in the field of informal logic, and that they are the basic building blocks of reasoned argumentation (Walton et al. 2008).

Rather than seeing the argumentation in Pollock's red light example as an inductive form of reasoning, it can be represented using an argumentation scheme for argument from perception identified in (Walton et al. 2008, 345).

Major Premise To have a $\varphi$ image (an image of a perceptible property) is a prima facie reason to believe that the circumstances exemplify $\varphi$.

Minor Premise Person $P$ has a $\varphi$ image (an image of a perceptible property).

Conclusion It is reasonable to believe that $\varphi$ is the case.

In (Walton et al. 2008, 345), only one critical question is given as matching the scheme for argument from perception, $\mathrm{CQ}_{1}$ : Are there circumstances giving a reason to think that P's having a $\varphi$ image may not be a reliable indicator of $\varphi$ ?

The use of this critical question can be illustrated by the example given by Pollock. In Pollock's example $(1995,53)$, the reasoning used fits the scheme for argument from perception. The person observes an object that appears to be red, and concludes that it is red. The reason that he accepts the statement that the object is red is that it appears to him to be red. Hence the scheme fits Pollock's example. The reasoning is defeasible, and is a typical instance of plausible reasoning. The claim that the object is red can be defeated if the object was being illuminated by a red light, because being illuminated by a red light makes any object appear red, even if it is not. So, for example, the object could be green, even though in these circumstances it appears to $\mathrm{P}$ to be red.

\section{Eikotic Argument}

Plausible reasoning was familiar in the ancient world, due to the Sophists, who used it to plead cases based on argumentation from eikos, from plausibility, from what "seems likely". " Eikotic arguments are based on a person's recognition of a situation that is of a type he is familiar with as normal or comprehensible in light of

\footnotetext{
${ }^{1}$ Plausible reasoning was attacked by Plato, as part of his general denunciation of the Sophists, and this attack created a strong prejudice against plausible reasoning throughout the history of philosophy.
} 
common experience (Tindale 2010, 69-82). Eikotic arguments are not conclusive, for a proposition that appears true to one observer may appear to be false to another. Thus it is possible to have reverse eikotic arguments on two sides of a disputed case. Two Sophists, Corax and Tisias, who lived around the middle of the fifth century B.C. provided the classic example in the ancient world (Gagarin 1994, 50). This reverse eikotic argument was attributed to Corax by Aristotle (Rhetoric 1402a17-1402a28), but Plato (Phaedrus 273a-c) attributes the example to Tisias. In this case, there was a fight between two men, and each accused the other of being the instigator and assaulting him. One of the men was visibly smaller and weaker than the other man. He argued that it was not plausible that he would instigate the fight by assaulting the bigger and stronger man, knowing that he would have little chance of victory. But the bigger man argued that it was not plausible that he would attack such a visibly weaker man, knowing that such an action would look bad for him in court. The example shows how plausible reasoning shifts a weight of evidence to one side or the other in a case, and how it is based on appearances. First, it is based on how the situation appeared to the two pleaders, and was presented by each of them as a story or account of what supposedly happened. Second, it has to do with how these competing accounts, as related in court, appeared to the jury. That is, the two pleaders draw on common notions of likelihood that would be familiar to the jury. Antiphon (who is the best represented of the fifth-century Sophists in terms of the material available) produced a series of texts intended as teaching tools to demonstrate the use of this method of arguing. He provides pairedtrial speeches, where first the prosecution speaks, then the defendant, with each subsequently responding to the other's claims. The sense of what is at stake in these examples of plausible reasoning can be gathered from the first exchanges of the first example Antiphon provides. A man has been murdered. His known enemy is the accused, and a slave accompanying the murdered man has identified the accused as the perpetrator, before himself dying from blows sustained in the assault.

The prosecutors set the tone by indicating how difficult it is to detect and expose crimes that have been carried out by natural criminals who plan their acts carefully with strict attention to not getting caught. Because of this the jury "must give the utmost weight to any indication whatever of plausibility (eikos) that is presented" (Diels and Kranz 1952, 87 B1: 2.1.2). They then issue a series of eikota or, in the initial move, what is not eikota:

It is not plausible that professional criminals killed this man, as no one would give up an obvious and achieved advantage for which he had risked his life, and the victims were found still wearing their cloaks. Nor again did anyone who was drunk kill him, since the murderer then would be identified by his fellow guests. Nor would the victim be killed because of a quarrel, since people would not quarrel in the dead of night and in a deserted spot. Nor was it a case of a man aiming to kill someone else and killing the victim, because then his attendant would not have been also killed (2.1.4).

Each implausibility is accompanied by a supporting reason, all of which are open to challenge, but the sum of which shifts the weight of proof in the prosecution's favor. Clearly people could quarrel in the dead of night and at a deserted spot; this is 
not denied. But given the jurors' experience of how people behave, how plausible is this?

Following these negative suggestions, attention shifts to what is plausible, in the prosecution's opinion: "Who is more likely to have attacked him than an individual who had already suffered great injuries at his hands and could expect to suffer greater ones still?" (2.1.5). Details of the past history between the two are then given to support this plausibility. Since the defendant was an old enemy of the murdered man and had brought several unsuccessful cases against him; since he had been indicted by the dead man on several cases, all of which he lost at the cost of much property; and since he bore a grudge for this, then it "was natural for him to plot against him, and it was natural for him to seek protection from his enmity by killing his opponent" (6-7). Here the plausibility is supported by claims about what a man of this nature would do. The prosecutors sum up by insisting that the jury cannot acquit the defendant because "conclusions from plausibility (eikota) and from eye-witnesses have alike proved" his guilt (10).

Figure 1 illustrates plausible reasoning from the body of factual evidence in this case to a plausible hypothesis about a defendant's motive, and the subsequent chain of reasoning from the motive to the ultimate conclusion that the defendant is the one most likely to have attacked the victim. The text box at the top right contains the statement that the defendant bore a grudge for these losses to the victim. This statement expresses a motive for the crime. The motive is used as a premise for a divergent argument to the two propositions to the left of it in Fig. 1. The four text boxes above the line are plausible hypotheses that are linked to each other as plausible arguments.

The six text boxes in the four arguments beneath the line are factual statements brought forward by the prosecution in the case, taken to represent evidence to support the hypothesis that the defendant's motive was a grudge against the victim. As shown in Fig. 1 at the top right, the argumentation scheme for this argument is the one for argument from evidence to a hypothesis $(\mathrm{EH}+)$, presented in detail in Sect. 9. The factual evidence put forward by the prosecution is used to support a hypothesis about an agent's motive.

This example represents a paradigm instance of plausible reasoning of a kind that is extremely common both in legal reasoning and in everyday conversational reasoning (Walton 2011). It is classifiable as plausible reasoning because we can never be sure of another person's motives or intentions, basically because of the socalled problem of other minds. This problem is that we do not have direct access to the mental states of other persons. Consequently when we make judgments about motives, intentions, or other mental states, it is a conjecture based on reasoning from evidence to a hypothesis. It is a commonplace of argumentation in criminal law that presumptions about an agent's motive or intention on based on plausible reasoning from a given body of factual evidence in a case. As shown in Fig. 1, once the hypothesis is put forward that the defendant bore a grudge for these losses to the victim, two conclusions follow naturally by plausible reasoning. One is that it was natural for the defendant to plot against the victim. The other is that it was natural for the defendant to seek protection from the victim's enmity by killing him. Inferences reasoning to a hypothesis about an agent's state of mind, however, are 


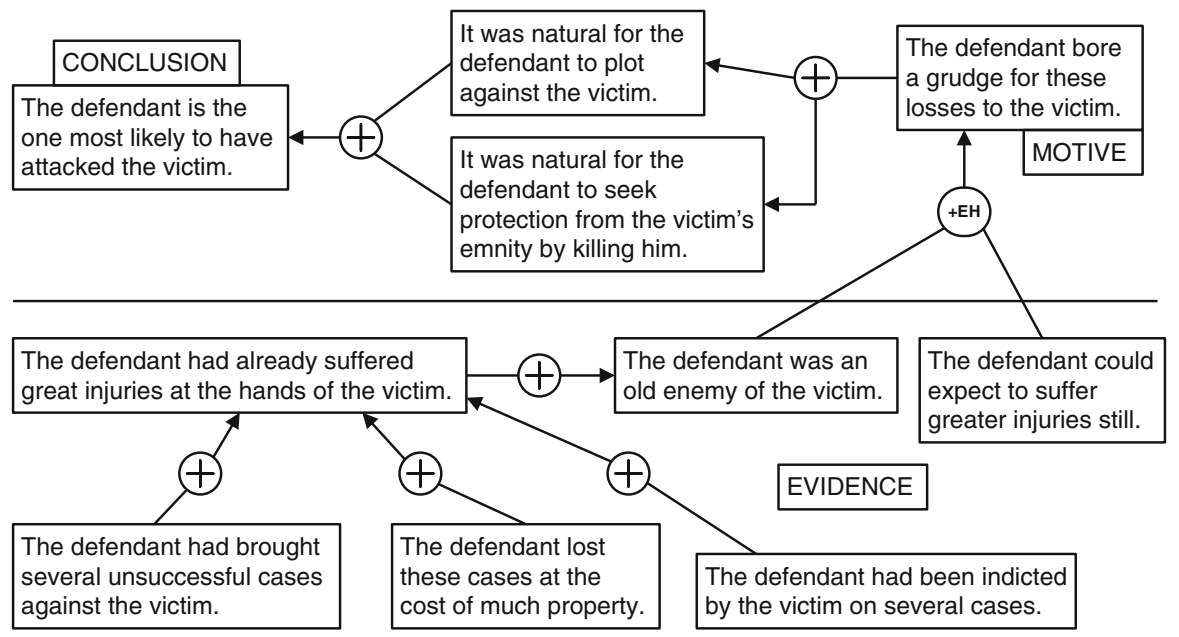

Fig. 1 Plausible reasoning to and from a motive in the murder example

somewhat difficult to use as examples of plausible reasoning, because of their inherent complexity. Below, however, a simpler example of direct plausible reasoning based on argument from perception will be taken from a source in ancient philosophy and used as our primary example to illustrate plausible reasoning.

In the defendant's opening speech he matches the plausibilities that have been brought against him and provides the following important rebuttal:

They assume me to be a fool. For if now, because of the magnitude of my enmity, you find me guilty on the grounds of plausibility (eikotôs), it was still more natural for me to foresee before committing the crime that suspicion would devolve upon me as it has done, and, if I knew of anyone else who was plotting the murder, I was likely to go as far as to stop them, rather than to deliberately fall under obvious suspicion (2.2.3).

The strategy here is to rebut one plausibility by advancing another that is more plausible. It is also noteworthy that Antiphon supplies the defendant with a variant of the same argument employed by Corax and/or Tisias, to the effect that since he was the most plausible candidate it is implausible that he would actually have done it. ${ }^{2}$

We can see the rationale for the strategy being employed here. Having no firsthand experience of the events relayed, and in the absence of other reliable evidence (like eye witnesses who can be cross-examined) the jury is thrown back on their own experience of what kinds of events are plausible, and it is on the basis of how well the accounts they are given match this experience that they will have to decide the case.

In the original Corax/Tisias example, by an act of empathy, a juror could put himself into the situation just before the fight began. Then the juror can ask a hypothetical question. Would he, if he were the smaller man, assault the bigger man

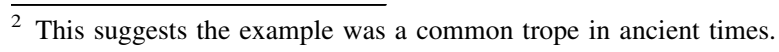


and start a fight with him? The answer is that there is a lot to be said against it. Why? The reason has to do with the known or expected consequences of the action. The expected outcome is that the smaller man would take a painful beating, and experience a humiliating defeat. The person on the jury draws the conclusion that the larger man's allegation that the smaller man started the fight is implausible. It might be true, but there is something to be said against it.

One of the most interesting things about the example is that it is a typical sophistic argument that can be turned on its head. According to the description of the example given by Aristotle (Rhetoric 1402a11), the larger man could use the following counter-argument. Since I am visibly so much larger and stronger than the smaller man, it was apparent to me that if I were to attack him, it would certainly look bad for me in court. ${ }^{3}$ Tindale $(2010,83)$ showed that the bigger and smaller man example is a peritrope, a turnaround argument of the kind favored by several Sophists. This kind of argument has often been called the turning of the tables, because it uses the very same kind of argument to attack an original argument. Tindale (2010) showed that many of the strongest instances of plausible reasoning found in the examples of the Sophists fit this pattern. In these examples, a plausible argument is put forward, and is then challenged as implausible by a comparable argument put forward by its opponent. In other words the original argument that was claimed as plausible, is shown by the counterargument to be implausible, or at least less plausible than it was originally taken to be. The effect of such an argument is to reverse it from being plausible to not being plausible. Gorgias, the well-known Sophist, employs this strategy in his Defense of Palamedes, where Palamedes defends himself against the charge of having a contradictory character by reversing the charge and making the same accusation of his accuser, Odysseus:

You have accused me in the indictment we have heard of two most contradictory things, wisdom and madness, things which cannot coexist in the same man. When you claim that I am artful and clever and resourceful, you are accusing me of wisdom, while when you claim that I betrayed Greece, you accuse me of madness. For it is madness to attempt actions which are impossible, disadvantageous and disgraceful, the results of which would be such as to harm one's friends, benefit one's enemies and render one's own life contemptible and precarious. And yet how can one have confidence in a man who in the course of the same speech to the same audience makes the most contradictory assertions about the same subject? (Diels and Kranz 1952, 82 B1:1a25).

In more modern terms, the bigger man's argument, as well as the original argument of the smaller man, can be classified as instances of the argumentation scheme for argument from negative consequences. The two argumentation schemes for argument from consequences are, respectively, argument from positive consequences and argument from negative consequences (Walton et al. 2008, 332).

\footnotetext{
3 It may appear that both arguments are equally plausible, but Aristotle sees a difference, writing (Rhetoric 1402a 11) that only the one is "probable absolutely". However, he does not explain what he means by this.
} 
Premise If $A$ is brought about, good consequences will plausibly occur.

Conclusion Therefore $A$ should be brought about.

Premise If $A$ is brought about, then bad consequences will occur.

Conclusion Therefore $A$ should not be brought about.

In this instance, the argument fits the scheme for argument from negative consequences. The larger man alleges that he is aware of the likely negative consequences of his attacking a smaller man. It would be imprudent for him to do it. This argument is persuasive because of common knowledge about the way things can normally be expected to go. Common knowledge, as understood here, is not just a matter of an individual's subjective judgment, but depends on a level of agreement about human experience. As long as any person on the jury is aware that the larger man would be aware of these consequences, he too can appreciate why the larger man would be reluctant to assault the smaller man. So by a kind of act of empathy, and an awareness of facts that would be familiar to both jurors and participants in the example, each member of the jury can draw a plausible inference. This inference gives a reason why it is implausible that the larger man would attack the smaller man. It can be seen that there are plausible arguments on both sides. This factor distinguishes plausible reasoning: a statement can be plausible while its opposite (negation) can also be plausible. This kind of case can occur where there are plausible reasons for accepting the statement as true, but also plausible reasons for accepting it as false.

The structure of the argument used by the larger man to reach his conclusion on what to do can be represented in Fig. 2 as an argument map. The argument is represented by the node (the rounded figure), while the statements in the argument, the premises and conclusions, are represented as text boxes (leaves). The argument map has the form of a sideways tree structure with the conclusion at the left. The notation -AN in the left node represents argument from negative consequences.

As shown in Fig. 2, the ultimate conclusion is the proposition shown at the extreme left, the statement that the bigger man attacked the smaller man. This is the proposition that has to be proved by the prosecution. There is a plausible argument on each side. The node represents the argument, and contains information about it, for example its argumentation scheme.

The argument representing the side of the smaller man is shown at the top of Fig. 2. It is an argument from negative consequences that is a common argument, an argument supporting the claim that it is implausible that the smaller man attacked a bigger one. The argument for its being implausible that the smaller man attacked the bigger one is that the smaller man would most likely be beaten and humiliated if he were to launch such an attack (and he would presumably know that), and being beaten and humiliated are negative consequences. The opposed argument is shown below this argument. It is also an argument from negative consequences. It is a con argument against the ultimate conclusion that the bigger man attacked the smaller. The argument given is that if the bigger man were to do this it would look bad for him in court (an presumably he would know that) and looking bad in court is a negative consequence for him. 


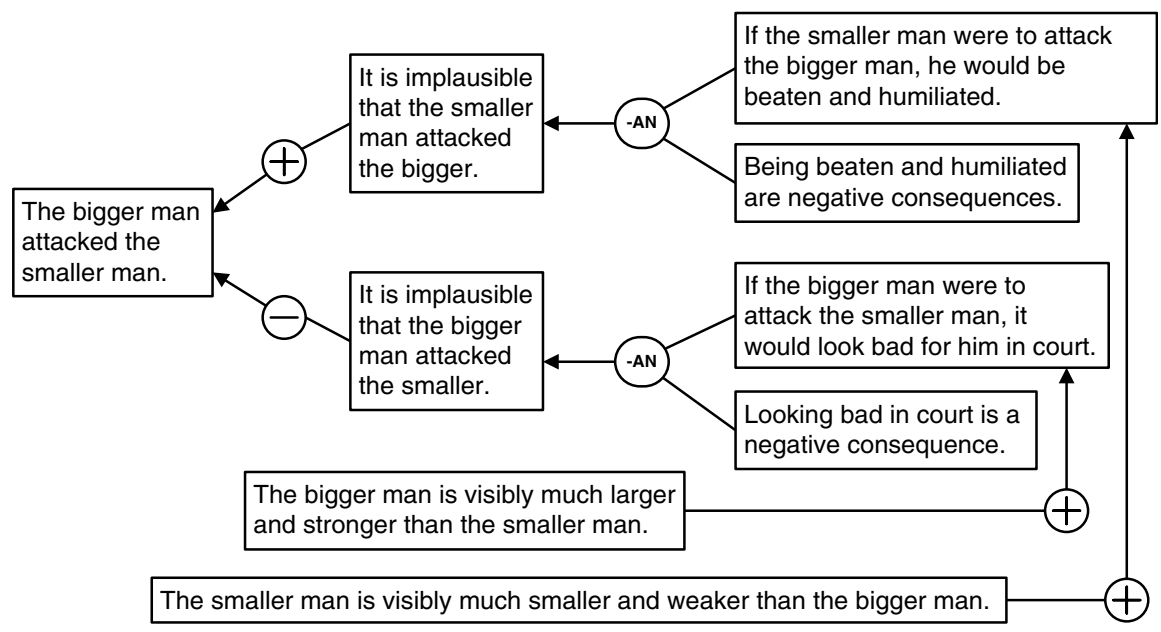

Fig. 2 Argument map of the bigger and smaller man example

The two plausible arguments are balanced against each other. The outcome of the trial depends on which argument is the stronger of the two, and whether one of them, taken with any other evidence in the case is stronger enough to meet the standard of proof required.

Not every argument on an argument map has an identifiable argumentation scheme. For example each of the two statements at the bottom is the premise of an argument that leads by inference to the statement at the top part of the diagram. This part of the example illustrates how the conclusion of one argument can be used again as a premise in another argument. This form of argumentation is called argument chaining and sometimes called a serial argument structure.

So far we have seen how to construct an argument map that displays the structure of an argument, including information about any parts of the argument that fit a known argumentation scheme. So far, we are only identifying and analyzing arguments, but another important task is that of evaluating them. To help us get a grasp of what plausible reasoning is, it is helpful now to make some remarks about argument evaluation.

The plausible inference in the example only carries some weight, all other factors in the case being equal. If the smaller man was known to be an experienced pugilist, whereas the larger man was not, the evidence in the case would be changed. This fact could explain why the smaller man had reason to think that he could win the exchange, or at least put up a good fight. This new fact would tend to alter the evidence in the case, and detract from the plausibility of his earlier argument. So a plausible inference can be defeated by new facts that enter a case. But plausible inference is different from probable inference, as shown by Rescher's account (1976, pp. 31-32) of the functional differences between the two types of reasoning. For example, in the probability calculus, the probability of a statement not- $A$ is calculated as $1-\operatorname{pr}(A)$. In the ancient example of plausible inference, this equation will not work. It is plausible, other things being equal, that the smaller man did not 
start the fight, for the reason given. But it is also plausible, other things being equal, that the larger man did not start the fight. But it is an assumption of the case that either one or the other (exclusively) started the fight. In other words, if one started the fight, the other didn't. From a point of view of probable inference then, if it is highly probable that one of them started the fight, it can't be highly probable that the other did. But from a point of view of plausible inference, even though it is plausible, other things being equal, that one started the fight, it can also be plausible, other things being equal, that the other started the fight. The reason, as indicated above by Rescher's account of plausible reasoning, is that plausibility is localized to the body of evidence on the one side of the controversy. As is typical of many legal cases, there are two competing "stories", or accounts of what supposedly happened (Pennington and Hastie 1991). Each one can be fairly plausible internally, and in relation to the body of evidence that exists. That body of evidence can be incomplete, so it may not rule out plausible accounts on both sides. It is for this basic reason, as Rescher has emphasized, that plausible inference is inherently different from probable inference.

Tindale $(2010,81)$ has provided a useful summary of six leading characteristics of plausible reasoning, based on recent findings in argumentation studies.

1. Plausible reasoning proceeds from premises that are more plausible to a conclusion that was less plausible before the plausible argument was brought to bear on it.

2. Something can be found plausible when hearers have examples in their own minds of what is being said.

3. Plausible argument is based on common knowledge of the kind shared by the party who puts the argument forward and the party to whom the argument was directed.

4. Plausible reasoning is based on defeasible inferences and generalizations.

5. Plausible reasoning is based on everyday human experiences of the way things can be generally expected to go in familiar situations.

6. Plausible reasoning can be used to fill in implicit premises in incomplete arguments where a premise or conclusion has not been explicitly stated.

Plausible reasoning has fallen out of favor because it seems to be too subjective to be reliable for logical reasoning. Plato encouraged this prejudice when he associated it with "whatever is accepted by the crowd" (Phaedrus 273a), thus suggesting it is arbitrary. However this perception is a misunderstanding of how eikotic arguments work (Tindale 2010, 81). Characteristic 2 seems subjective, but that overlooks characteristics 3 and 5, which show that commonality is an important part of plausible reasoning. Plausible reasoning is based on common knowledge shared by speaker and hearer, and is therefore not dependent solely on the hearer's subjective view. It is this appeal to customary experience that makes plausible reasoning so useful in a trial setting, especially where the trier is a jury. It is not surprising that many of the examples of plausible reasoning used by the Sophists were court cases.

Plato's attack on plausible reasoning in the Phaedrus (273a) was serious because of the way it suggested that plausible argument is no better than appeal to popular 
opinion, a form of argument that has been categorized in logic as a fallacy. However, recent work on fallacies has also turned that around, and it is now becoming more widely accepted that arguments based on what is generally accepted, although defeasible, are often reasonable when used under the right conditions.

\section{Carneades' Theory of Plausible Reasoning}

Plato's views did not always hold sway, even in the Academy. A positive notion of plausible reasoning was refined and developed by the later Platonic Academies, culminating in the theory of Carneades (c. 213-c.128 B.C.), the head of the third Platonic Academy. Carneades' theory of plausible reasoning arose as a reaction against the Stoics' epistemological claim that there is a reliable criterion of acceptance based on their notion of the cognitive impression. They claimed that such a cognitive impression gives a perfectly accurate grasp of an object that is being clearly perceived and thereby provides a criterion for determining that the content of the impression is true. The Academics attacked this claim using familiar skeptical arguments based on examples of deceptive appearances. This attack, however, left them open to the objection that they had no criterion for acceptance that could guide the sage in making decisions for action. It was to respond to this objection that Carneades put forward his theory of plausible reasoning which allowed the sage to accept impressions that are merely plausible. Even though such an impression cannot be known to be true beyond all doubt, provided the sage realizes that its acceptance is defeasible, he can reasonably accept it. However the Stoics had another objection ready. If the sage is to guide his conduct by reason, he cannot simply accept impressions that are plausible, because he might act in a frivolous way (Allen 1994, 89). Carneades' theory of plausible reasoning can be seen as a reply to this objection. On his theory of acceptance, initial impressions can be subjected to tests. For example, they can be tested against other impressions. If the initial impression fails the test, acceptance of it can be retracted. If the initial impression passes the test, it can be confirmed as more plausible than before, giving an additional reason for accepting it.

Carneades' theory of rational acceptance is an alternative to the realist truth of the Stoics. On his theory, we can judge the plausibility of an impression as it relates to the subject experiencing it instead of judging it as it relates to the externally existing object. On his theory, things appear to be true and false to different degrees. In other words, plausibility can be weighted as stronger or weaker (Groarke 1990, 114).

Carneades' theory holds that an appearance given as an impression can be accepted provisionally as plausible to the extent that it meets three criteria. First, it is plausible if it appears to be true. Second, it is even more plausible if it appears to be true and is stable, meaning that it is consistent with other propositions that appear to be true. Third, it is even more plausible if it can be tested and passes the test. This introduction of testing to resolve questions of plausibility is a considerable advance of what we were given by Antiphon whose examples were more open ended. To 
grasp the theory, several key examples reported by Sextus Empiricus are extremely useful to consider.

The second criterion, according to Sextus (AL 176) is that the presentation (appearance) should be both plausible in the first sense, and also stable. Sextus presented a medical example. A physician will conclude that a man has fever not only from one symptom, like rapid pulse or high temperature, but also on a concurrence of other symptoms, like soreness of touch or thirst (AL 179-180). Each impression shows stability of the one(s) before it by being consistent with what is suggested by the prior one(s). The third criterion is that it is even more plausible if it is stable and tested, and passes the test. Sextus presented the following example: "when we are investigating a small matter we question a single witness, but in a greater matter several, and when the matter investigated is still more important we cross-question each of the witnesses on the testimony of the others" (AL 184). According to this tripartite theory of Carneades, any proposition we should accept based on data (appearances), should only be provisionally accepted in the form of a hypothesis that is subject to doubt.

Carneades' leading example is that of the rope and snake, reported by Sextus Empiricus (AL 188), quoted from the Loeb Library translation (1938, 101-102).

For example, on seeing a coil of rope in an unlighted room a man jumps over it, conceiving it for the moment to be a snake, but turning back afterwards he inquires into the truth, and on finding it motionless he is already inclined to think that it is not a snake, but as he reckons, all the same, that snakes too are motionless at times when numbed by winter's frost, he prods at the coiled mass with a stick, and then, after thus testing the presentation received, he assents to the fact that it is false to suppose that the body presented to him is a snake.

The man sees what looks like a coil of rope in a dimly lit room, but based on how it appears, and on the uncertainty of seeing it clearly in the dim room, he adopts the hypothesis that it is, or could be, a snake. Acting on this assumption, and on practical concern for safety, he jumps over it, and then turns back afterwards and sees that the object has not moved. Consistent with these new data, he switches to the hypothesis that the object is a rope. Taking a third step, he prods it with a stick. Again it does not move. This test confirms the hypothesis that the object is a rope, and not a snake, as first thought. In this example, we see all three criteria applied.

The writings of Cicero are important sources for our understanding of Academic methodology, because he had read the numerous books written by Clitomachus, a student of Carneades who succeeded him as head of the Academy. Cicero himself was also an advocate and practitioner of the Academic method. Cicero understood the academic method as "a dialectical inquiry that, by arguing for and against all views, reveals the one that is most likely to be true" (Thorsrud 2002, 4). Cicero also identified Carneades as a practitioner of the same method. On Cicero's account, Carneades' criterion of acceptance, which Cicero called probabilitas, is implied both in decision making in the conduct of everyday life and in philosophical inquiry (Thorsrud 2002, 5).

The Greek term pithanon used by Carneades and the Academics was translated into Latin using the term probabilitas (Allen 1994, 89). According to Long (1974, p. 97), this term pithanon literally means "persuasive" or "trustworthy", but 
according to Allen 1994, 89), it means "approvable", as a basis for action or inquiry. The term "acceptable" might also not be out of place, referring to tentative acceptance of a statement subject to possible later retraction if new evidence comes in. Since the advent of the statistical notion of probability in the Enlightenment, the term 'probability' has taken on a different meaning, however, making this translation now highly misleading. Because of the unfortunate translation of Carneades' theory using the term 'probability', it has been traditionally assumed that it represents an outdated, incorrect and misguided ancient theory of the modern Pascalian notion of probability.

What is especially interesting to observe here is that Carneades tested his own arguments against the views of the Stoics, and against the objections that the Stoics made to his arguments in turn. Thus the way he developed his philosophical view was through a dialectical exchange with the Stoics. He was not merely attacking their views for the negative purpose of attempting to refute them. He took part in a probing exchange of argumentation with his opponents and this enabled him to build up evidence supporting his own views as worthy to respond to plausible objections. Thus he not only had a theory of rational acceptance, but also had a dialectical methodology used to provide evidence to support his theory. Long (1974, 85) wrote that it is now well understood that the methodology of the Academics was dialectical, meaning that their method for the testing of the plausibility of a statement was to subject a claim to testing through an examination in a Socratic style of dialogue.

Carneades' theory was a way of overcoming skeptical suspension of judgment in the face of uncertainty which is characteristic of normal human actions and observations (Bett 1990, p. 3). In such a pragmatic approach, what can be taken to be true should be based on what it is reasonable to provisionally accept as a plausible hypothesis, even though new evidence in the future may show that it is refuted. Carneades' theory of plausible reasoning, viewed in this way, can be seen as a precursor of the notion of defeasible reasoning now so important in artificial intelligence. A plausible proposition in this sense is one that is acceptable provisionally, as a hypothesis, because it appears to be true, and there is no reason to think that it is false yet, even though the knowledge collected so far is incomplete. Plausible reasoning, so conceived, is a response to the problem of reasoning under uncertainty in a constantly changing world of data as discovery and investigation move forward from a slightly plausible hypothesis to a more plausible one.

\section{Locke and Bentham on Plausible Reasoning}

John Locke (1726) used the notion of plausible reasoning to support his theory of degrees of assent in chapter fifteen of his Essay Concerning Human Understanding. Locke defined "probability", or what should properly be called plausibility, by contrasting it with demonstration. Demonstration yields certainty. As an example of a demonstration, Locke cited a proof in Euclidean geometry (1726, 274). Arguments based on plausibility occur in cases where something "appears, for the most part to be so". (273), but where there is lack of knowledge and, hence, no basis in certainty 
on which we can say the proposition is true. To illustrate plausibility, Locke presented the example of the Dutch ambassador who was entertaining the king of Siam (275-276). The ambassador told the king that water in the Netherlands would sometimes, in cold weather, be so hard that men could walk on it. He said that this water would even be so firm that an elephant could walk on the surface (276). The king found this story so strange that he concluded the ambassador had to be lying. The story makes the point that plausibility refers to an inference drawn on the basis of normal, commonplace expectations based on conditions that a person is familiar with. Indeed, this example fits well with the earlier Greek cases that depended on common experience. In the tropics, people were not familiar with freezing conditions, and hence the story of the freezing canal did not fit in with the normal expectations the king of Siam had of his environment. The king just found the ambassador's statements implausible and unconvincing.

To show how plausible reasoning is important in common kinds of argumentation such as legal evidence, Locke used the example (283) of evidence based on witness testimony. The reason for drawing an inference from witness testimony to a conclusion about what happened in a case is that the witness was, it is supposed, a direct observer of the event in question as it appeared. Such testimony supplies what Locke called good proof of the conclusion claimed. But if the testimony was based not on direct observation but on the claimant having heard it from another witness, it will be weaker. Each step of inference from the direct observational testimony of the original source will weaken the plausibility of the evidence (283).

Locke recognized the distinction between deductive and plausible reasoning, using syllogistic reasoning as his example of the former. Judging their uses and value comparatively, he hypothesized (298) that although syllogistic reasoning is useful in science and with reasoning based on knowledge, it is of "far less, or no use at all" in areas like legal reasoning and everyday argumentation, under conditions of lack of complete or conclusive knowledge. According to Locke's assessment, deductive reasoning does not have the flexibility needed to make it as useful as plausible reasoning where there is uncertainty about matters that are subject to dispute. What the implications of Locke's recognition of the importance of plausible reasoning had for his theory of knowledge is an issue too broad to be taken up here. Suffice it to say that Locke recognized plausible reasoning, contrasted it with deductive reasoning, and even argued that in many instances the former is a better tool for analyzing and evaluating arguments than the latter.

Jeremy Bentham was also familiar with plausible reasoning and employed it as the basis of his theory of legal reasoning about evidence. Bentham developed what he called a natural theory of evidence, meaning it was free of artificial restrictions and was based on the same notion of probability, or probative force that is used in everyday reasoning outside the trial context. In Bentham's natural system, there are two parts to plausibility (Bentham 1962). One is the establishing of the plausibility of a proposition, and the other is the testing of that plausibility by a subsequent process of examining it. As shown above, Carneades' method of testing a hypothesis about the content of an appearance is to test it against other appearances. Bentham's notion of plausible reasoning is comparable. He held that such a 
hypothesis could be tested by examining it, by testing it against other appearances, and by critically questioning it.

What is even more interesting is Bentham's drawing of a distinction between probability in the statistical sense, or what has come to be known as the Bayesian sense, and what we have called plausibility. He indicated awareness of such a distinction by discussing whether plausibility can be measured by some number or ratio of numbers of the kind we are familiar with in handling statistical data. He wrote (64) that, on an individual occasion, the degree of strength at which a persuasion stands "would be capable of being expressed by numbers, in the same way as degrees of probability are expressed by mathematicians, viz. by the ratio of one number to another."

Bentham's method of evaluating plausibility is his so-called system of securities for testing the trustworthiness of a proposition put forward as plausible, for example, by a witness. ${ }^{4}$ The degree of plausibility of a proposition can be calculated, according to Bentham, by a formula. The outcome is a function of the initial probative force of the evidence supporting it minus the probative force of any of the contrary indicators (Twining 1985, 55). Another part of the system involves a sequence of inferences called by Bentham (Volume 7, 2) a "chain of facts". Bentham described such a chain of facts (2) as originating in a so-called "principal fact", which leads, by a series of links, to succeeding evidentiary facts drawn by inference from the principal fact and from the previous conclusions drawn in the sequence of inferences. Bentham then went on to discuss (Volume 7, 65) cases where there is an evidentiary chain composed of a number of links. Evaluating the plausible reasoning in such a chain is based on the principle that "the greater the number of such intermediate links, the less is the probative force of the evidentiary fact proved, with relation to the principal fact" (65). As the chain grows longer, the inference gives less plausibility for accepting the ultimate conclusion in the chain because the chain is weakened. As an example, Bentham cited the following case (65): "The more rounds a narrative has passed through, the less trustworthy it is universally understood to be." The notion of the chain of reasoning is a familiar one both in modern argumentation theory and in artificial intelligence.

Bentham anticipated three hypotheses that have come to be taken seriously in current artificial intelligence models of legal reasoning (Bex et al. 2003). One is that plausible reasoning should not be evaluated in the same way as inductive and statistical reasoning, by the Bayesian method of attaching numbers to the premises and conclusion of an argument and then calculating prior and posterior probabilities using the axioms of the probability calculus (Schum 1994). The second is that chaining of plausible argumentation into a network of connected premises and conclusions represents an important step in the evaluation of evidence. The third hypothesis is that in such chains of arguments, the evidence as a whole needs to be evaluated by using a weakest link principle. Bentham's system is highly compatible with the kind of approach advocated by Wigmore in which the whole body of evidence in a case (after a trial) can be represented as a network of propositions

\footnotetext{
${ }^{4}$ It should be recalled that when reporting the views of Carneades, Sextus used the example of testing plausibility by cross-examination of witness testimony in a trial.
} 
connected by inferences. Wigmore (1931) even used argument maps (called Wigmore charts) to evaluate such masses of evidence collected on one side of a case during the trial process in which two sides presented opposed arguments on a central issue. Wigmore's use of argument diagramming tools foreshadowed recent argument mapping tools now used in artificial intelligence such as CAS.

\section{The Carneades Argumentation System}

In this section we outline the special features of CAS that enable it to be applicable to the ancient examples we are concerned with. CAS is a mathematical model consisting of definitions of mathematical structures (Gordon et al. 2007). It is also a computational model, meaning that all the functions of the structures are computable. CAS defines mathematical properties of arguments used to identify, analyze and visualize instances of arguments. CAS models the structure and applicability of arguments, using argumentation schemes and an argument mapping tool built into its graphical user interface (http://carneades.github.com/). The argument maps used to analyze the example in the next section are simplified representations of this tool.

In CAS (Gordon and Walton 2006) once it is determined which premises of an argument are accepted by the audience or not, the system can calculate the acceptability of the conclusion. The CAS method of determining the acceptability can be summarized as follows (Gordon and Walton 2006).

- At each stage of the argumentation process, an effective method (decision procedure) is used for testing whether some proposition at issue can be taken as plausibly true given the arguments of the stage and a set of assumptions.

- The assumptions represent the commitments or beliefs of the audience.

- This determination may depend on the proof standard applicable to the proposition at issue, given the dialogue type and its protocol.

- What is used is a decidable acceptability function provided by the Carneades model of argument.

CAS adjudicates between pro and contra arguments by applying a standard of proof to each individual statement in the argument and propagating values across argument structures. It can use different standards, including numerical ones as well as balancing of comparative probative weights that are not calculated numerically. The differing proof standards allow for flexibility in styles of argument evaluation.

The CAS software is available on the internet at the site http://carneades.github. com/. An example of the CAS user interface is shown in Fig. 3. Note that a newer, web-based version of CAS is under development with a new model of argument evaluation that can handle cyclic argument graphs. This new version is also available from the same web site.

The statements in the argument are shown in the menu at the top right of Fig. 3. There is another menu (not shown) that is used to select the standard of proof. In this instance, the standard of the preponderance of the evidence has been selected, as shown by the weight figure of +.50 given in the node. The user can assign each 


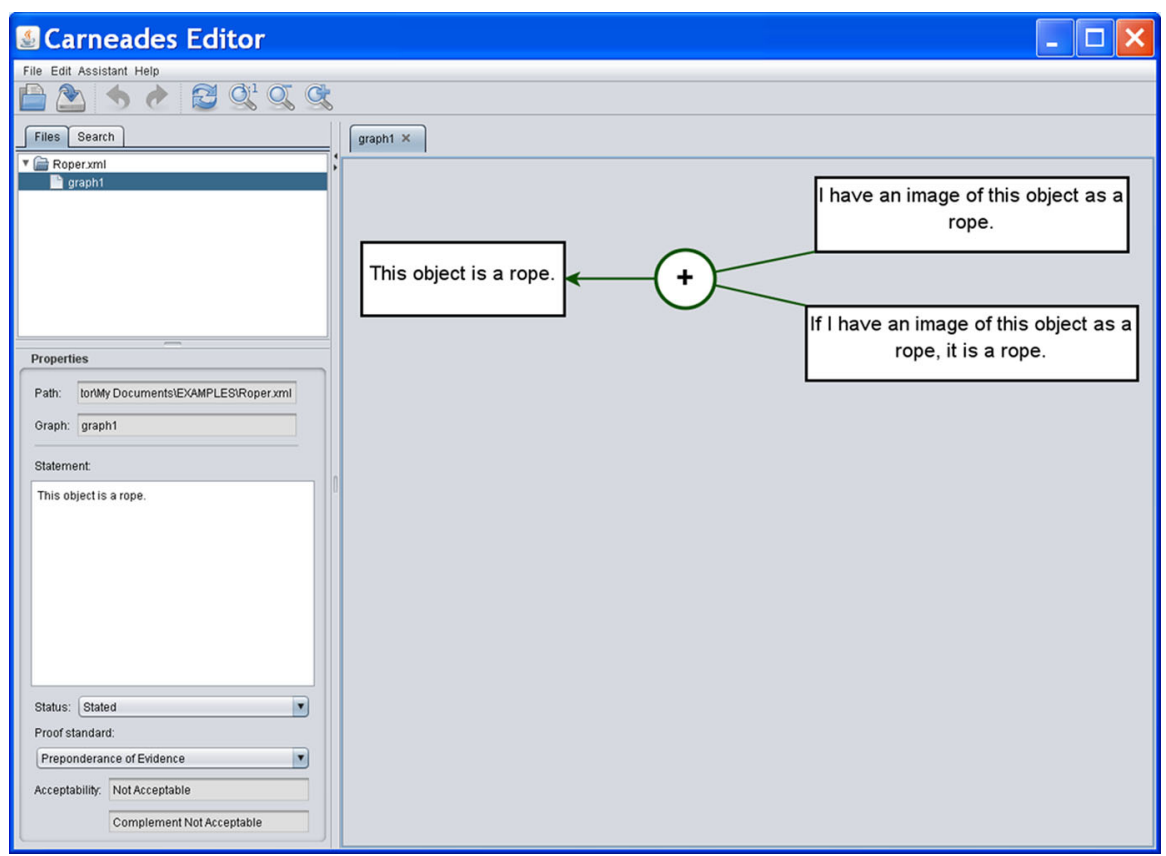

Fig. 3 Graphical user interface of Carneades

proposition one of four values, 'stated', 'questioned', 'accepted', or 'rejected'. A proposition that is stated appears in text box with a white background, a proposition that is accepted appears in a green text box, a proposition that is questioned has a question mark in front of it and appears in a white text box, and a proposition that is rejected appears in a red text box. Based on the values for the initial statements given as premises in the text boxes, and values for the defeasible arguments, an appropriate color will appear in the conclusion box. For example, the proof standard of preponderance of the evidence has been inserted by the user in the menu at the left of Fig. 3. The propositions in the text boxes are all stated.

In CAS arguments are evaluated by putting in values for each proposition that appears in a text box in an argument graph based on (1) standards of proof and on (2) whether the audience to whom the argument was directed accepts that proposition or not (Gordon and Walton 2009). Once the user puts in these values, CAS automatically goes over the whole argumentation tree built to represent the chain of reasoning in a case and adjusts their values up or down depending on the structure of the argument tree, the standard of proof and the argumentation schemes. Technically, audiences are modeled as a set of assumptions and an assignment of weights to argument nodes (Gordon and Walton 2011). The proof standards employed by CAS have legal applications in mind, but they can also apply to everyday reasoning cases, as we hope to show below by an example from the philosopher Carneades. The preponderance of the evidence standard, also known as the balance of probabilities, is the standard applicable to civil cases in law. The 
preponderance standard is met by a proposition if the strongest pro argument is stronger than the strongest con argument. Note however that the pro and con arguments are not collectively compared against each other, for example by summing their weights. Other standards used in law are the clear and convincing evidence standard and the beyond reasonable doubt standard.

\section{How CAS Applies to the Murder Example}

Figure 1 can be used once again to illustrate how argument evaluation works in CAS. Figure 1 is the argumentation tree (Prakken et al. 2003) that has been constructed in order to provide an analysis of the structure of the argumentation as a tree chaining together premises and conclusions that lead toward an ultimate conclusion to be proved. In a modern common law criminal case, the beyond reasonable doubt standard would be applied. However, since this is an ancient case, the best we can do is to conjecture what standard of proof the audience might have applied. Nevertheless, we can evaluate the argument as follows. All the text boxes below the line can be darkened. If we used the CAS visualization tool online, provided the audience accepts the six propositions below the line, each text box would be colored green. Assuming the arguments are all reasonable as plausible arguments the four argument nodes below the line would also be colored green. Assuming the argument from evidence to a hypothesis fits the requirements of the argumentation scheme for that type of argument, the EH+ node would also be colored green. On this basis, CAS would also color the motive text box green. Assuming that the statement attributing motive to the defendant supports the two conclusions to the left of it shown in the divergent argument, both these text boxes would also be colored green. Finally, once the last step is taken to the ultimate conclusion, it is colored green. This completes the pro argument, but we also have to consider the defendant's con argument.

It can be shown how the defendant's strategy in his opening speech presents a con argument that can be mapped onto the original argument put forward by the prosecution as shown in Fig. 1. The defendant's argument accepts, or at any rate does not dispute any of the evidence showing under the line in Fig. 1. It does not deny that the defendant might have born a grudge for these losses to the victim. In other words, it does not dispute the prosecutions claim that the defendant had a motive for killing the victim. Instead, it mounts a counterargument that attacks the conclusion that the defendant is the one most likely to have attacked the victim. It carries out this argument by attributing a different motive to the defendant, based on assumptions about common knowledge and plausibility that would apply to the case. The defendant argues that it would be even more natural for him to foresee that committing the crime would throw suspicion upon him as the murderer. By his own common knowledge of what is plausible, the audience should accept that the defendant would know that if he was plotting the murder, suspicion would immediately fall upon him as the murderer. The reason is that everybody, including the defendant, knew all the factual evidence displayed in Fig. 1 below the line. Everybody knew that the defendant was an enemy of the victim, that he had lost 
court cases to the victim at the cost of much property, and so forth. Given all this easily verified common knowledge, it can be easily appreciated by the audience (the jury) that the defendant would be very aware that he would be the primary suspect if the victim were to be murdered. We could also draw up an argument diagram showing how this plausible line of reasoning rebuts the conclusion that the defendant is the person who is most likely to have attacked the victim and killed him. We will stop short of doing this, however, as we have now shown well enough how the CAS can be applied to an example of this sort. It can be compared with how CAS applies to modern legal cases (Gordon and Walton 2012).

CAS applies naturally to this example, not surprisingly, as the system is specifically designed to be used to model legal argumentation. However, it is a much tougher test to see how CAS could be applied to the example of the snake and the rope. The man who decides to jump over the object that looks like it might possibly be a snake in a dark room is not directing his pro and contra arguments to an audience, for example a jury. He is a solitary agent who is deliberating on what to do in a situation that demands choice.

The "audience" is in this special case is the person doing the reasoning. This is just an example of monological argumentation, where one argues with oneself. In CAS the audience is a role, not a person. In a dialogue, the audience is the respondent. In a court case, the audience is the judge and jury. In monological argument, one person plays all the roles (proponent, respondent, audience,...). In general, the audience is whomever needs to be persuaded by the arguments. He is asking what he should do in this tricky situation, and examining the pro and con arguments in order to arrive at a reasonable decision on what to do.

To apply CAS to this example it needs to be argued that by weighing the pro arguments against the con arguments, the man faced with the decision on what to do needs to play the role of devil's advocate. He needs to adopt certain thoughtful attitude of neutrality as he finds all the most significant arguments both for and against the course of action is contemplating, and then in light of the possible consequences and other relevant factors, he has to weigh the arguments on one side against those on the other side and make a decision about which course of action is best supported by the evidence based on plausible reasoning. To do this, as we will now show, he must use the critical questions matching the argumentation scheme for argument from perception, construct a hypothesis, and then compare the pro and con arguments supporting or rebutting the hypothesis.

\section{Argument from Perception Modified}

The argument from perception will be centrally important in the next example we study, the famous rope and snake example, and is fundamental to understanding how CAS will be applied to this example. In the account of argument from perception given by Walton et al. (2008, 345), as shown in Sect. 2, there is only one critical question matching the scheme for argument from perception. It is will now be argued that to fit a CAS style analysis of the structure of argument from perception, two other critical questions need to be added. 
$\mathrm{CQ}_{2}$ Are there other images that $\mathrm{P}$ has that suggest that $\mathrm{P}$ 's having a $\varphi$ image may not be a reliable indicator of $\varphi$ ?

$\mathrm{CQ}_{3}$ What test has been made, if any, that would confirm or cast into doubt whether P's having a $\varphi$ image is a reliable indicator of $\varphi$ ?

Let's consider $\mathrm{CQ}_{2}$. To show that a proposition is accepted the text box is darkened (indicating green), and if an argument holds its node is shown as darkened.

Let's suppose that several people have observed the object and report that they see it as red, but other evidence shows that the object is giving off a wave length that does not fit the red part of the spectrum. This would suggest that the object may not be red after all, despite the applications of the argument from perception suggesting defeasible that the object is red. Thus argument from perception is defeasible, meaning that it only holds tentatively and is subject to defeat as new evidence comes into a case being considered. This characteristic is typical of plausible reasoning.

\section{The Rope and Snake Example}

In this section we go through the leading example of the Academic philosopher Carneades in a step by step fashion by analyzing the structure of each of the component arguments in the longer chain of argumentation that makes up the example. The first statement asserts that the man in the example sees a coil of rope in an unlighted room. It says in the text of the example that when the man sees the coil of a rope in the unlighted room he jumps over it, conceiving it for the moment to be a snake. However, it appears to be presumed that initially he saw the object as a rope, before conceiving it for the moment to be a snake. To represent this part of the argument, we can use the scheme called argument from perception, identified in Sect. 2. As applied to the example, the first premise says that to have a rope image is a reason to believe that the circumstances exemplify a rope. The second premise is that the person has a rope image. The conclusion is that it is reasonable to believe that the object that he sees is a rope. This argument is defeasible, as illustrated by example. For although the man first of all sees the object as a rope, and takes it to be a rope, for whatever reason he concedes it for the moment to be a snake, temporarily changing his mind (Fig. 4).

The structure of this first component argument is displayed in Fig. 5. In this part of the argument we have two premises that combine in an argument from perception to support the conclusion that the object seen can be identified as a rope.

At the next stage of the argumentation in the example, the man jumps over the object he has seen, conceiving it for the moment to be a snake. Here we see a sequence of practical reasoning that leads the man to carry out an action, presumably based on the assumption that this action is prudent in the circumstances. He sees what looks like a coil of rope, but the room is unlighted. Why would he act in such a manner, given that for all he knows, the object he sees could be either a rope or a snake? Evidently the reason is one of safety. It takes very little effort to jump over the object, and since there is a possibility it could be a snake, he decides 


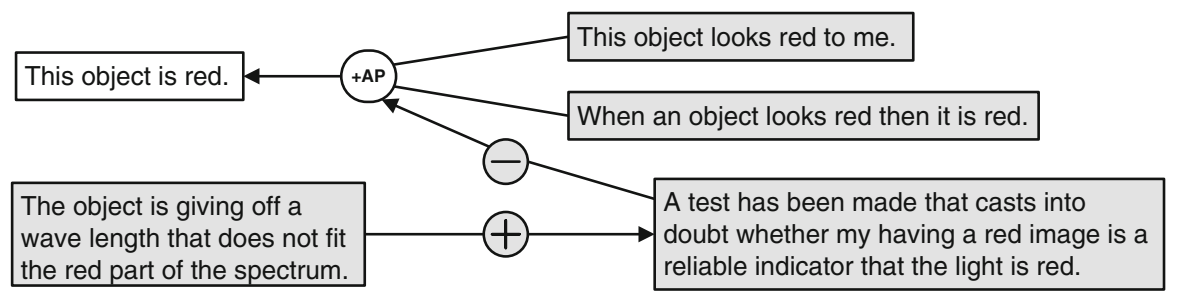

Fig. $4 \mathrm{CQ}_{3}$ as modeled by CAS

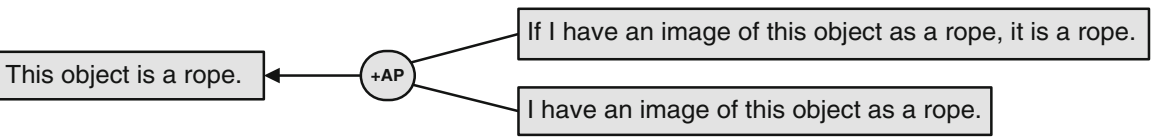

Fig. 5 First argument step in Carneades' example

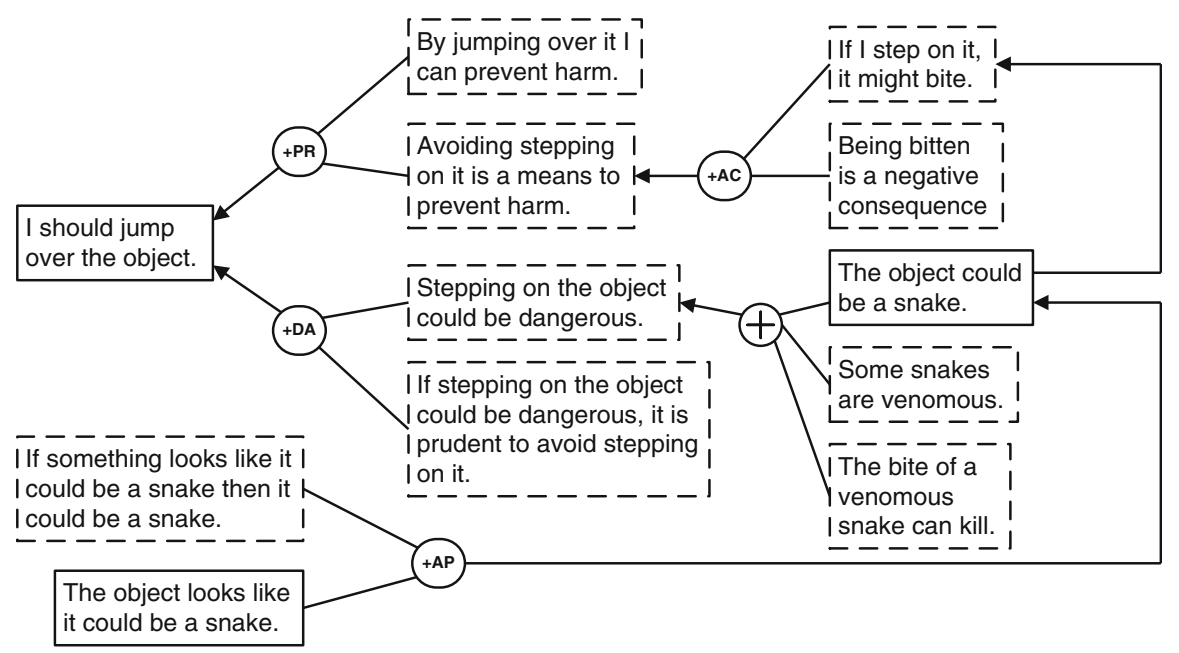

Fig. 6 Second version of the implicit premises shown in the second step of the argument

to do that rather than to step on it. Evidently then, there are some implicit assumptions in the chain of reasoning that leads him to the course of action to jump over the object. We can reconstruct the argument by putting in these assumptions as implicit premises, as shown in Fig. 6.

This interpretation of the argument goes much deeper by bringing out more implicit premises. It represents the person's thinking as he steps into the darkened room and decides what to do by using practical reasoning. PR represents the scheme for practical reasoning. AP represents Pollock's version of the argument from perception. 
DA represents the scheme for argument from danger (Walton 2000, 173).

If you (the respondent) bring about $A$ then $B$ will occur.

$B$ is a danger to you.

Therefore (on balance) you should not bring about $A$.

A danger is something that is especially harmful to the respondent, for example involving injury or life-threatening harm. Reasoning under these conditions errs on the side of safety by making presumptions to avoid harm.

In the next step of the argument, the man in the example changes his mind, illustrating defeasibility. Turning back afterwards, the man conducts a further investigation by looking at the object, and finds it motionless. For this reason he is now inclined to think that it is not a snake. The structure of this part of the argument can be represented by using the argumentation scheme for argument from evidence to a hypothesis. This scheme admits of two subtypes (Walton et al. 2008, 331) called, respectively, argument from verification and argument from falsification.

Major premise If $A$ (a hypothesis) is true, then $B$ (a proposition reporting an event) will be observed to be true.

Minor Premise $B$ has been observed to be true, in a given instance.

Conclusion Therefore, $A$ is true.

Major premise If $A$ (a hypothesis) is true, then $B$ (a proposition reporting an event) will be observed to be true.

Minor Premise $B$ has been observed to be false, in a given instance.

Conclusion Therefore, $A$ is false.

In this instance, a part of the argument can be seen to fit the argument from falsification. The major premise is the statement that if the object is a snake, it would have been observed to move. The minor premise is the statement that the object was not observed to be moved. The conclusion is the statement that the object is not a snake. Arguments from evidence to a hypothesis are in many cases also instances of abductive reasoning, or inference to the best explanation. The scheme representing this type of argument was shown in Sect. 2, following the account of Josephson and Josephson (1994), to take the form of an inference to the best explanation. In this form of reasoning, the hypothesis represents the best explanation of the given facts (the evidence) in the case at hand.

The structure of this stage of the argument can be visualized as shown in Fig. 7. The darkened boxes represent the green color that would appear in CAS. In this instance, we have visualized the argument by supplying the generalization that a snake moves if you jump over it as an implicit premise based on common knowledge of the way things can generally be expected to go in a normal situation. This statement is shown as an implicit premise in the text box at the bottom right of Fig. 7. To apply the scheme for abductive reasoning to this example we could reason as follows: the best explanation for the object's not moving when the man jumped over it is that it is not a snake. 


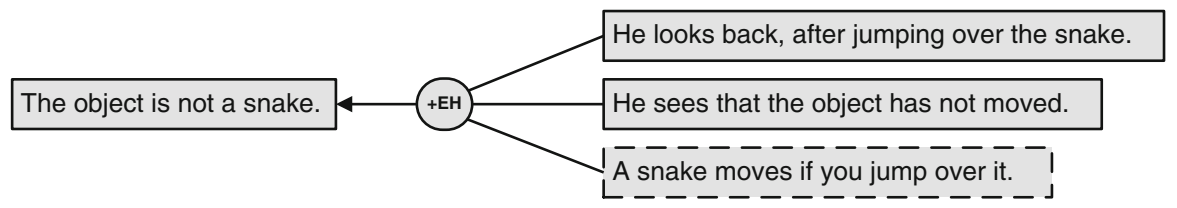

Fig. 7 Instance of argument from evidence to a hypothesis

It is very important to observe, in light of the analysis of the next step of the argument below, that this instance of argument from evidence to a hypothesis is defeasible. In other words, if at the next stage the object were to be seen to have moved, the prior conclusion that the object is not a snake has to be retracted. This feature can be brought out by examining the critical questions matching the scheme for argument from evidence to a hypothesis (below).

$\mathrm{CQ}_{1}$ Is it the case that if $A$ is true then $B$ is true?

$\mathrm{CQ}_{2}$ Has $B$ been observed to be true (false)?

$\mathrm{CQ}_{3}$ Could there be some reason why $B$ is true, other than its being because of $A$ being true?

The third critical question, as applied to the example, asks whether there could be some other reason why the object did not move. This will be shown when we proceed with the next step, where this factor comes to be relevant.

At the last step of the argument, the man is inclined to think that the object is not a snake, based on the generalization that a snake moves if you jump over it. But now, he reckons, snakes are motionless at times when numbed by winter's frost. The feature of argumentation that emerges very clearly here is defeat of a generalization in a premise. If this is a time when snakes are numbed by frost, the generalization that a snake moves if you jump over may not apply in these circumstances. Given the assumption shown in Fig. 8 that it is winter, the generalization that snakes are motionless when numbed by winter's frost.

This part of the chain of argumentation in the example is shown in Fig. 8. In the bottom node in Fig. 8, information is given about the type of argument as proceeding from the special circumstances of the case. Since it is accepted that it is winter, and it is accepted that snakes are motionless at times when numbed by winter's frost, the implicit premise shown in the text box with the broken line is not accepted. Hence the argument from evidence to a hypothesis is no longer applicable. Thus the ultimate conclusion is not accepted.

Now we proceed to the final step in the argument. At the previous step, the man had changed his mind again, and considered that the object may be a snake. At the next step, he tests this hypothesis by prodding it with a stick. After testing the presentation this way, he assents to the fact that it is false to suppose that it is a snake. This part of the argumentation can be analyzed as shown in Fig. 10. The notation in the node indicates that the argumentation in this part of the snake case fits the scheme for abductive reasoning. The best explanation for the coiled object not moving (of the alternatives being considered) is that it is not a snake. 


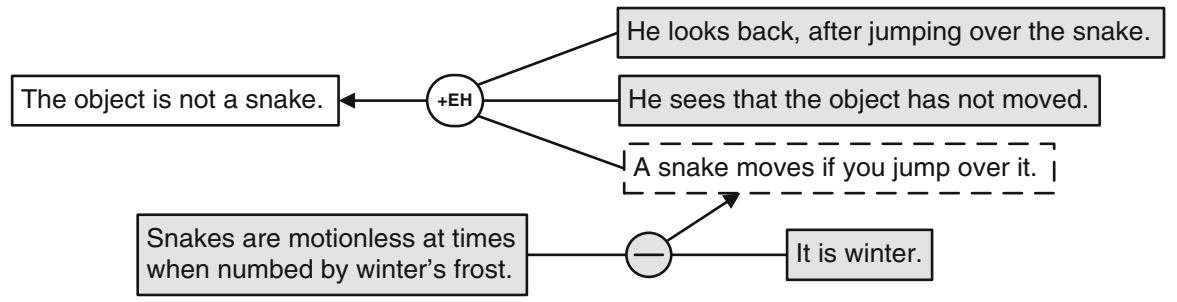

Fig. 8 A counter-argument to a premise in the example

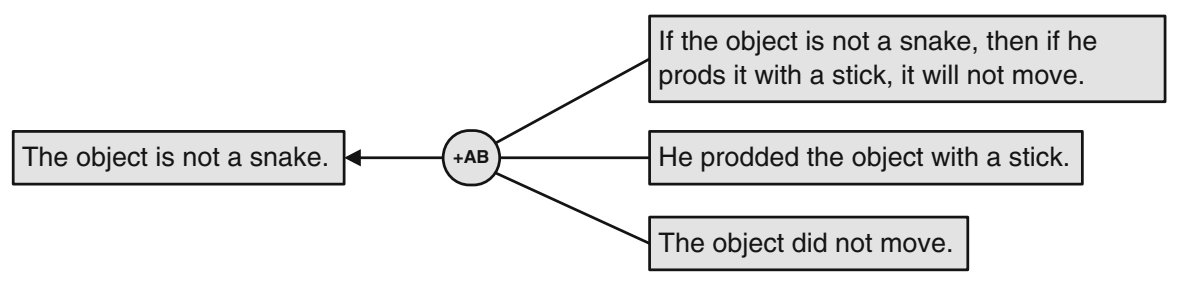

Fig. 9 Testing the object in the example

As the argumentation in the example has proceeded, the man has changed what he assented to several times. In Fig. 2, the conclusion is that the object is a rope. In Fig. 5, he jumps over the object, thinking that it could be a snake. In Fig. 4, the conclusion of his argument is the statement that he is inclined to think it is not a snake. In Fig. 5 his conclusion is that, all now considered, the object may be a snake. In Fig. 9, he assents to the fact that it is false that the object is a snake.

\section{Conclusions}

This paper has shown that there was a continuous thread of recognition of plausible reasoning as an alternative to the deductive and inductive models of reasoning that so dominated the history of logic. Through Locke and Bentham the notion of plausibility survived as the basis of a kind of reasoning that could support rational acceptance of an inference leading to a conclusion, based on something other than deductive reasoning or inductive probability. Thus there was a connection joining the ancient notion of plausible reasoning to the modern one that has now been deployed in artificial intelligence. The evidence for this connection reinforces the theory of the historical development of ideas traced by Twining (1985) through the Lockean and Benthamite notion of plausible reasoning to the influential theory of legal evidence developed by Wigmore (1931). In this paper, a variant on Wigmore's argument maps supplied through the artificial intelligence argumentation system CAS has brought out significant features of two ancient examples of plausible reasoning, the rope and snake example and the bigger and smaller man example. A close connection between artificial intelligence and ancient philosophy has been revealed. 
This paper only dealt with these examples insofar as they can be used for defining plausible reasoning as distinct from more familiar deductive and inductive modes of reasoning. Carneades' theory, however, admits for evaluation of plausible reasoning by application of its three criteria for comparatively weighing how strong an argument is. Evaluation can be carried out in the rope and snake example by assigning weights to each text box and each node in the argument map. These weights can be expressed numerically, or by using an ordering so that they are compared to each other as stronger or weaker.

One hypothesis we considered was to distinguish seven stages of plausibility assessment, so that the plausibility value of a proposition is increased as it reaches each higher stage. These seven stages are only relevant for abductive reasoning, which is a particular argumentation scheme, or class of schemes, and does not cover all of plausible reasoning. Also we need to qualify our claim by pointing out that abductive reasoning does not cover all instances of arguing from evidence to a hypothesis, but is used during the discovery stage of a scientific inquiry.

\section{Seven Stages of Plausibility Assessment}

1. plausible but uncorroborated

2. plausible and corroborated

3. plausible but untested

4. plausible and tested

5. plausible and tested but uncorroborated

6. plausible and corroborated but untested

7. plausible corroborated and tested

These seven stages can be displayed in a plausibility Table 1 means that it has been corroborated (or tested). 0 means that it has not been corroborated (or tested). ? means that it is not known whether the proposition in question has been corroborated (or tested) or not.

The table reflects the difference between a case of a proposition that is untested and one where it is not known whether it has been tested or not. Similarly, there is a difference between a case where a proposition is said to be uncorroborated and a case where it is said that it is not known whether it has been corroborated or not.

These four values are input values, representing assumptions about the audience. They are not values inferred from the arguments and audience. The output of the evaluation of the argument graph has three values (in, out, undecided), where "in" means the statement is acceptable, "out" means the negation of the statement is acceptable, and "undecided" means that neither the statement nor the negation of the statement is acceptable. The strengths of these inferences are measured by the chosen proof standard, e.g. preponderance or beyond reasonable doubt. Here then the notion of an audience plays a vital role, a view that the ancient philosopher Carneades would have liked.

At the present stage of our investigations, we are inclined to think that the plausible reasoning in all the ancient cases we considered can be modeled by the existing CAS with its four input values. These values, as the reader will recall from 
Table 1 Three-valued plausibility table

\begin{tabular}{llllllll}
\hline Stage & 1 & 2 & 3 & 4 & 5 & 6 & 7 \\
\hline Plausible & 1 & 1 & 1 & 1 & 1 & 1 & 1 \\
Corroborated & 0 & 1 & $?$ & $?$ & 0 & 1 & 1 \\
Tested & $?$ & $?$ & 0 & 1 & 1 & 0 & 1 \\
\hline
\end{tabular}

Sect. 6, are the following: stated, questioned, accepted, and rejected. Our current view is that we can adequately analyze and evaluate the argumentation in all the ancient examples we have presented by using CAS provided that we define the basic characteristics of plausible reasoning in a clear manner, and that we model the testing function that was so prominent in the rope and snake example by using argumentation schemes, for example the scheme for argument from perception.

The three key arguments in the rope and snake example are displayed in Fig. 10. At the top, there is the original argument from perception leading to the conclusion that the object is a rope, basically because it looks to the person in the example like a rope. Both premises, as well as the node representing the argumentation scheme are shown in in darkened text boxes, meaning that they have been accepted. For this reason the conclusion, the statement that the object is a rope, is also shown in a darkened box. So far, the argument provides some evidence that the object is a rope, and therefore, along with an implicit premise, provides enough evidence to conclude that the object is not a snake. But this is only the first argument, and it is defeasible. At the middle level, there is the argument from evidence to a hypothesis to the conclusion that the object is not a snake. The evidence here was provided by the person's jumping over the snake and observing that it did not move. All three premises of this argument are shown in darkened boxes. However, also shown is an undercutter that defeats one premise of the argument, namely the statement that a snake moves if you jump over it. For this reason, the argument node for argument from evidence to hypothesis is shown with a white background, meaning that it is stated but not accepted.

Finally, at the bottom level, there is the strongest argument for the conclusion that the object is not a snake. This abductive argument has three premises, and assuming that they are accepted, they are shown in darkened boxes. Since the argument node is also shown in darkened node, this argument provides a reason to accept the conclusion that the object is not a snake. Hence what is shown in Fig. 10 is that we have three arguments supporting the conclusion that the object is not a snake. Both the top argument and the bottom one support the conclusion that the object is not a snake. The middle argument would also provide an argument to support the conclusion that the object is not a snake, but one of its premises is defeated by a counterargument support.

Note that the argumentation displayed in Fig. 10 is not yet a complete reconstruction of Carneades' original example. Figure 10 does illustrate abduction but it does not illustrate the practical reasoning part of the argumentation shown in Fig. 6. As practical reasoning, the top argument would conclude that the object is a snake, because coiled things look like snakes, snakes are dangerous, and it is safer to 


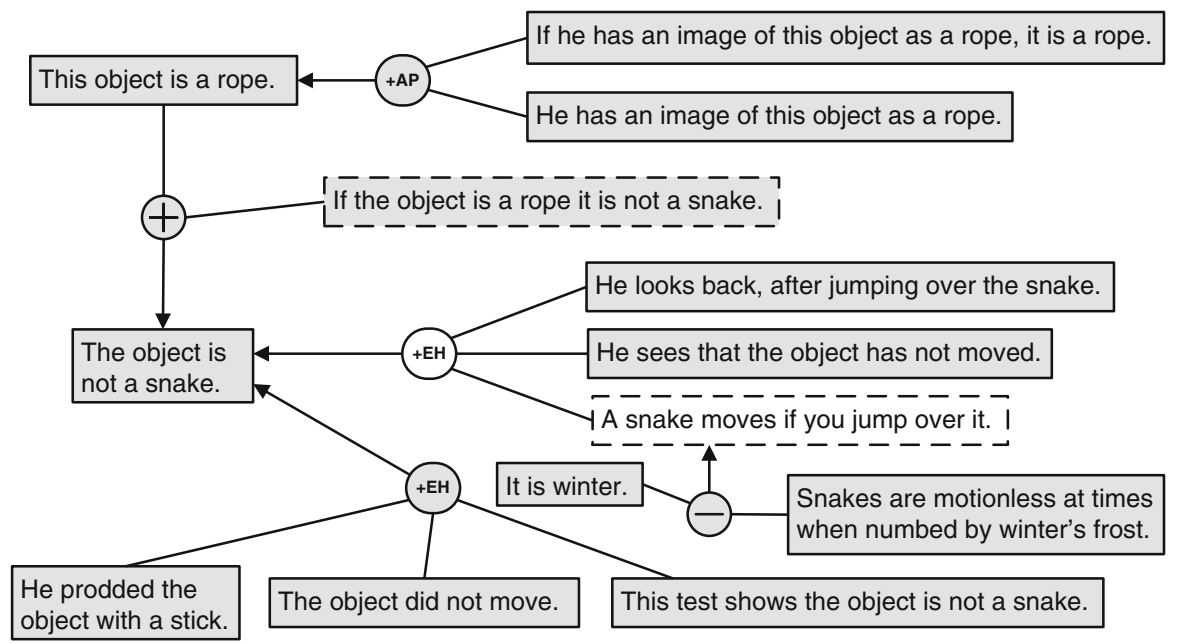

Fig. 10 Evaluating the arguments in the rope and snake example

conclude that things which look like dangerous things are dangerous. This differs from abduction, because it takes the risks of making a mistake into account. Using abduction, the best explanation for the observation that the object is coiled might well be that it is a rope, not a snake. But using practical reasoning, one might choose to believe some explanation which is not best, to avoid risks. The argument from practical reasoning could be included by adding it to Fig. 10, but we will not do this here, as Fig. 10 illustrates well enough for present purposes how CAS applies to the example.

Another aspect the argument map in Fig. 10 does not show is how the plausible reasoning becomes stronger as the argumentation proceeds from the top to the bottom through its three stages. In Carneades' example, it would appear from our interpretation of it that the top argument is fairly weak, the middle argument would be stronger except that one of its premises is undercut, and the third argument is the strongest. The reason is that the third argument provides the most conclusive test. However, argument graphs in CAS do not yet display processes. This procedural view of abduction, with three steps, is not handled by CAS. That said, what can be handled by CAS is that an argument based on more evidence is stronger than an argument based on less evidence, possibly causing the conclusion of the argument to meet a higher/stronger proof standard. There may be a way to model this aspect of the reasoning using the standards of proof and by extending CAS to display processes in which new evidence is introduced to an existing argument to make that argument stronger. This cumulative effect of upgrading or downgrading the plausibility of a given argument is especially important for modeling abductive reasoning where a hypothesis is strengthened or weakened by new evidence, for example based on continued testing of the hypothesis. But CAS is not yet able to accomplish this modeling this kind of reasoning. This limitation indicates that CAS needs to be extended to model cumulative reasoning of the sort illustrated by 
Carneades' snake and rope example if it is to be successful to capture all the important features of argumentation present in the example.

The analysis of the snake and rope example has shown that four other characteristics of plausible reasoning can be added to the list of six from (Tindale 2010, 81) cited in Sect. 3, along with one more, giving a final total of eleven. First, plausible reasoning is commonly based on appearances (cognitive impressions) based on the scheme for argument from perception. Second, one instance of plausible reasoning can be strengthened or weakened by another. Stability is an important characteristic of plausible reasoning. For example, one argument from perception can be strengthened or weakened by another. Third, plausible reasoning can be tested, and by this means, confirmed or refuted. Fourth, probing into an argument based on plausible reasoning by the asking of critical questions in a dialogue is an important way of testing claims made on the basis of plausible reasoning. This fourth characteristic is the dialectical characteristic of the testing of plausible reasoning. In total, there are eleven characteristics of plausible reasoning that can be summarized as follows.

1. Plausible reasoning proceeds from premises that are more plausible to a conclusion that was less plausible before the plausible argument.

2. Something is found plausible when hearers have examples in their own minds.

3. Plausible reasoning is based on common knowledge.

4. Plausible reasoning is defeasible.

5. Plausible reasoning is based on the way things generally go in familiar situations.

6. Plausible reasoning can be used to fill in implicit premises in incomplete arguments.

7. Plausible reasoning is commonly based on appearances from perception.

8. Stability is an important characteristic of plausible reasoning.

9. Plausible reasoning can be tested, and by this means, confirmed or refuted.

10. Probing into plausible reasoning in a dialogue is a way of testing it.

11. Plausible reasoning admits of degrees by testing, but of a kind different from those the standard probability values and Bayesian rules used in Pascalian probability.

The eleventh characteristic is illustrated by the example of the rope and the snake. Each time the hypothesis of the classification of the object as a rope is found more stable or tested, it is confirmed as more plausible than before. It has greater probative weight. This process of evaluating by testing is characteristic of Pascalian probability.

CAS was relatively easily applicable to the murder case to exhibit how plausible reasoning is used in this case to construct a sequence of argumentation of a typical kind based on factual evidence in a legal case. But it seemed less easily applicable to the snake and rope case because there appeared to be no audience in that case that can be used as a basis for judging what is plausible or implausible. However, in the snake and rope example, the person who is trying to decide whether the coiled object is a snake or rope has to act both as arguer and audience. What he accepts a 
priori, as audience, is that he has observed a coiled object in a dark room and that coiled objects can be snakes (or ropes).

In the CAS, it is the audience who decides which premises in an argument should be accepted and which should be rejected. In other words, the decision whether a given proposition should be put into the system as plausible or not, depends on the audience to whom the argument was directed. So the problem is how this model can be applied to the snake and rope case. The detailed analysis of the argumentation in this case set out in Sect. 6 shows how this problem can be solved. The man in the example has to make a decision on what to do under conditions of uncertainty, and so he has to use defeasible arguments such as argument from perception, argument from negative consequences and argument from lack of evidence. In the analysis in Sect. 6, it was shown how these argumentation schemes are applied, and how they have to be fitted into the chain of argumentation and evaluated using critical questions matching each scheme. In other words, the person in the example has to examine the pro and contra arguments during the procedure of deliberation he goes through by asking critical questions and by this means finding counterarguments that would support the opposed side to the one he is currently considering. By engaging in this devil's advocate process, the decision-maker has to be his own audience. At the same time, he has to use common knowledge, for example common knowledge of the known and expected plausible consequences of any course of action he considers. In this regard, the decision-maker himself has to represent the audience.

But there is also another respect in which the decision-maker has to take an external audience into account. He might have to justify his action afterwards, by giving an explanation of what he did. For example someone might later ask him why he jumped over the object if it looked like a snake. Such a critic might say that this was reckless behavior. In order to defend himself against this charge, the man who jumped over the object in the dark room, even though it could possibly have been a poisonous snake, would have to resort to reconstructing the chain of argumentation he went through when he made that decision on the basis of the balance of the Baconian probabilities. The reasonableness of what he did or did not do in the given situation will be based on his account of why he accepted the premises and conclusions that he did, and how well this acceptance ties in with the acceptance of the audience, based on the common knowledge shared with the audience about what is reasonably acceptable or not in situations of this sort represented by the example.

CAS reflects the skeptical philosophical point of view in two important respects. The first is that it evaluates reasonable evidence-based argumentation using the notions of acceptance rather than truth. The second is that it does not see proof as being absolute in nature, or as arriving by deductive reasoning at a conclusion that can be proved to be true beyond all doubt. For both reasons, CAS nicely represents the philosophical views of the sceptical philosopher Carneades. But what is also shown is that Carneades was not, at least entirely, a skeptic. He started with a skeptical epistemology by raising doubts about whether knowledge requires truth, but used this skeptical approach to move forward to a theory of argumentation 
showing how we can, even as fallible perceivers of the real world, have evidencebased acceptance-based defeasible knowledge.

\section{Directions for Further Research}

CAS is still under development, and as shown in this paper, some important details of how it can be used for displaying and evaluating instances of plausible reasoning have not been worked out yet. By using Carneades' original example of the snake and rope, we have shown that one very important feature of plausible reasoning missing from the current version of CAS is some way to increase our confidence in some conclusion as possible con arguments have been considered and failed. As the number of con arguments which fail increases, so too does our confidence in the conclusion. In the snake and rope example, there are two con arguments, one for the additional evidence (not moving when jumping over the object) and one for the test (prodding with a stick). The problem that has been identified is that confidence does not increase as con arguments are put forward and fail. Proof standards do not help here, because the number or weight of failed arguments has no effect on the acceptability of some conclusion, no matter which proof standard is applied. We are currently working on a solution to this problem and hope to present it in another paper once our work is ready.

This present paper is meant to show at least how plausible reasoning, as known in the ancient world (and subsequently to Locke and Bentham) is a clear notion that has a place in argumentation studies. We realize that our analysis of the structure of the argumentation in the snake and rope example has brought out a limitation of the current version of CAS.

The paper has mainly been confined to identification and analysis of plausible reasoning. The characteristics of plausible reasoning above are central to identifying instances of plausible reasoning. The principle that both a statement and its negation can be plausible is important for the evaluation of plausible reasoning. This principle is represented in CAS, where arguments both pro and con a given statement can be acceptable. Keppens $(2009$, 93) observed that some versions of probability theory fit well with an argumentation framework consisting of a body of evidence made up of pro and contra arguments interacting with each other. In CAS arguments are evaluated using a tree structure of joined inferences representing pro and contra arguments and the root of the tree is the ultimate hypothesis to be proved or disproved. The pro and contra arguments in this system, along with the critical questions matching them, work as tests that the hypothesis passes or fails. As in the case of the bigger and the smaller man, evidence on one side can make a statement plausible to some degree, while evidence on the opposed side can make the same statement implausible to some degree.

It is also interesting to note that this approach to argument evaluation is consistent with contemporary theoretical work in argumentation such as, for example, the pragma-dialectical theory of van Eemeren and Grootendorst (2004). On this approach, arguments for and against the proposition are weighed against each other. This evaluation takes place during and after an argumentation procedure 
for resolving a conflict of opinions. In the pragma-dialectical approach (van Eemeren and Grootendorst 2004, 132), the conception of reasonableness required to solve the problem of when a proposition can properly be said to have been justified by the evidence put forward to support it needs to be based on a procedure in which pro and contra arguments along with the critical questions are used to test the arguments on each side. The procedure for resolving the conflict by closing off the discussion in favor of one side or the other can be based on the standard of proof appropriate for the discussion. For example, the standard of the preponderance of the evidence could be used in a critical discussion. By applying this standard, if the evidence marshaled by one side presents an argument that is stronger than the argumentation put forward by the other side, then the first side has resolved the conflict of opinions in its favor. Indeed, it is our contention that the existing argumentation methods, such as argument diagrams, argumentation schemes, the critical discussion framework, and the other methods we used, can be applied to the ancient examples with promising results.

The standard argumentation procedure of weighing the pro arguments against the con arguments is governed by rules of discussion and argumentation, including a rule that sets in place a requirement of burden of proof. This approach is compatible with the view of plausible reasoning advocated by CAS, where a proposition can be justified as acceptable if there is an appropriate balance of pro arguments and con arguments relevant to the proposition, and the pro arguments, once aggregated, are stronger than the aggregation of the con arguments. By this means a proposition can be supported strongly enough on a balance of considerations to warrant its acceptance as a tentative basis for forming an opinion or making a reasonable decision.

Legal examples of argumentation and evidence turned out to feature prominently in this paper, suggesting another direction for further research. It has been shown that one of the most important applications of plausible reasoning is to the notion of probative weight in the law of evidence. This finding supports the view already articulated and defended by Twining (1985). It is shown how plausible reasoning is a distinct form of reasoning in its own right recognized by Locke, and Bentham, and how it is applicable to evidential reasoning in law. The example of the bigger and smaller man used to illustrate plausible reasoning clearly shows its legal import. One only has to look at modern rules of evidence in the Anglo-American system of law to see how the foundational notion of probative weight stemming from Carneades and the ancient skeptics influenced the notion of rational argument in the modern Anglo-American law of evidence through Locke and Bentham.

Further research is needed to show how plausible reasoning is related to abductive reasoning. The two concepts are closely related, and there has already been interesting and useful research carried out on the question of their relationship (Josephson and Josephson 1994), but we realize that this is another problem brought out by Carneades' example that we have not been able to fully solve. One reason is that there are open fundamental issues about how abductive reasoning should be defined, and even some disagreement among ourselves on how it ought to be modeled. Another interesting question raised by our analysis of the example is the relation between plausible reasoning and practical reasoning. As we showed, the 
snake and rope example can be treated as an instance of practical reasoning as well as an instance of abductive reasoning and argument from perception. However, being able to identify plausible reasoning is a helpful step toward tackling these fundamental questions of argumentation theory.

Bentham's method of evaluating plausible reasoning uses the example of witness testimony in law. The problem with evidence based on witness testimony is that such arguments are highly fallible, even though they are needed as evidence. The analysis in (Walton 2008) configures witness testimony as a defeasible form of argument based on a characteristic argumentation scheme, and specifies the appropriate critical questions that need to be asked in order to cast doubt on this form of evidence. In this model, argument from witness testimony is analyzed as a form of legal evidence that needs to be evaluated as a distinctive species of plausible reasoning. There was no space to cover all of these questions about legal evidence here, but a better understanding of how argumentation schemes and plausible reasoning work together is useful for approaching them.

Acknowledgments Doug Walton and Tom Gordon would like to acknowledge support from our Social Sciences and Humanities Insight Grant. All three of us would like thank the Centre for Research in Reasoning, Argumentation and Rhetoric for support of our work.

\section{References}

Allen, J. 1994. Academic probabilism and stoic epistemology. Classical Quarterly 44: 85-113.

Anderson, T., D. Shum, and W. Twining. 2005. Analysis of evidence, 2nd ed, 2005. New York: Cambridge University Press.

Aristotle. 1937. Rhetoric. Cambridge: Loeb Classical Library, Harvard University Press.

Bentham, J. 1962. The works of Jeremy Bentham, 7th ed. John Bowring: Russell and Russell.

Bett, R. 1990. Carneades' distinction between assent and approval. Monist 73: 3-20.

Bex, F., H. Prakken, C. Reed, and D. Walton. 2003. Towards a formal account of reasoning about evidence. Argument Schemes and Generalizations, Artificial Intelligence \& Law 11: 125-165.

Diels, Hermann, and Walther Kranz. 1952. Die Fragmente der Vorsokratiker. Berlin: Weidmannsche Verlagsbuchhandlung.

Gagarin, M. 1994. Probability and persuasion: Plato and early Greek rhetoric. In Persuasion: Greek rhetoric in action, ed. Ian Worthington, 46-68. London: Routledge.

Gordon, T.F., and D. Walton. 2006. The Carneades argumentation framework. In Computational models of argument: proceedings of COMMA 2006, ed. P.E. Dunne, and T.J.M. Bench-Capon, 195-207. IOS Press: Amsterdam.

Gordon, T.F., and D. Walton. 2011. A formal model of legal proof standards and burdens. In Proceedings of the seventh international conference of the international society for the study of argumentation, ed. F.H. van Eemeren, et al., 644-655. Amsterdam: SicSat.

Gordon, T.F., and D. Walton. 2009. Proof burdens and standards. In Argumentation and artificial intelligence, ed. I. Rahwan, and G. Simari, 239-260. Berlin: Springer.

Gordon, T.F., and D. Walton. 2012. A Carneades reconstruction of Popov v Hayashi. Artificial Intelligence and Law 20(1): 37-56.

Gordon, T.F., H. Prakken, and D. Walton. 2007. The Carneades model of argument and burden of proof. Artificial Intelligence 171: 875-896.

Groarke, L. 1990. Greek scepticism: anti-realist trends in ancient thought. Montreal: McGill-Queen's University Press.

Josephson, J.R., and S.G. Josephson. 1994. Abductive inference: computation. Philosophy, Technology, Cambridge: Cambridge University Press. 
Keppens, J. 2009. Conceptions of vagueness in subjective probability for evidential reasoning. In Proceedings of the 22nd annual conference on legal knowledge and information systems, ed. G. Governatori, 89-99. Amsterdam: IOS Press.

Locke, J. 1726. An essay concerning human understanding, 9th ed. London: A. Churchill.

Long, A.A. 1974. Hellenistic philosophy: stoics, epicureans, sceptics, 1974. London: Duckworth.

Pennington, N., and R. Hastie. 1991. A cognitive theory of juror decision making. Cardozo Law Review 13: 519-557.

Pollock, J. 1995. Cognitive carpentry. Cambridge: MIT Press.

Prakken, H., Reed, C. and D. Walton. 2003. Argumentation schemes and generalisations in reasoning about evidence. In Proceedings of the 9th international conference on artificial intelligence and law, 32-41. New York: Association for Computing Machinery (ACM).

Rescher, N. 1976. Plausible reasoning. Assen: Van Gorcum.

Schum, D.A. 1994. Evidential foundations of probabilistic reasoning. New York: Wiley.

Sextus Empiricus. 1938. Against the logicians. Cambridge: Loeb Classical Library, Harvard University Press.

Thorsrud, H. 2002. Cicero on his academic predecessors: the Fallibilism of Arcesilaus and Carneades. Journal of the History of Philosophy 40: 1-18.

Tindale, C. 2010. Reason's dark champions: constructive strategies of sophistic argument. Columbia: The University of South Carolina Press.

Twining, W. 1985. Theories of evidence: Bentham and Wigmore. London: Weidenfeld and Nicolson.

Van Eemeren, F., and R. Grootendorst. 2004. A systematic theory of argumentation. Cambridge: Cambridge University Press.

Walton, D. 2000. Scare tactics: arguments that appeal to fear and threats. Dordrecht: Kluwer.

Walton, D. 2008. Witness testimony evidence. Cambridge: Cambridge University Press.

Walton, D. 2011. Teleological argumentation to and from motives. Law, Probability and Risk 10(2011): 203-223.

Walton, D., C. Reed, and F. Macagno. 2008. Argumentation schemes. Cambridge: Cambridge University Press.

Wigmore, J.H. 1931. The principles of judicial proof, 2nd ed. Boston: Little, Brown and Company. 